\title{
CALL FOR PAPERS ]
}

\section{General information:}

https://annual.ametsoc.org/2021/

2021 Annual Meeting FAQs:

https://annual.ametsoc.org/index.cfm/2021/ about-the-meeting/faq-for-virtual-elements-ofthe-annual-meeting/

Abstract submissions:

https://ams.confex.com/ams/

\section{Call for Papers}

\section{AMS Annual Meeting \\ 10-14 January 2021, Virtual Meeting}

The 2021 AMS Annual Meeting theme is "Strengthening Engagement with Communities through our Science and Services". For the full description of the theme, please visit the AMS 2021 Annual Meeting web page.

We recognize the challenges all of us are facing regarding COVID-19 as well as the uncertainty around travel to New Orleans. Thanks to all that took the time to respond to the June survey regarding the 101st AMS Annual Meeting. An overwhelming majority of you noted, at that time, you were not comfortable traveling to New Orleans for in-person sessions. Given this, we moved all oral and poster sessions, panel discussions, and exhibits to a virtual format. We will also plan on having virtual networking opportunities and short courses available. AMS President Mary Glackin and her Overall Planning Committee are looking forward to leading the AMS into its next century by being adaptable and innovative. We feel the virtual platform will allow us to attract many new attendees and allow for a level of inclusiveness that is much higher than we have been able to have in the past.

We will continue to monitor the situation around COVID-19 and are looking into the options for a smaller, in-person meeting for those that would still like to gather, if it will be safe to do so. We are also considering encouraging our local chapters to host socially distant gatherings during the week of the 101st Annual Meeting. We will share more details on the Annual Meeting website as they become available.

The deadline for abstracts has passed. Authors of accepted presentations will be notified via email in early-November 2020. If an author is unable to present due to changes in meeting format, dates, or health reasons, AMS will refund the fee in full.

As we continue to share details on the planning over the next few months and will continue to update the 2021 AMS Annual Meeting FAQ's. Please reach out with any questions and be sure to send any suggestions along to meetings@ametsoc.org. Registration will open in mid-September, the program will be posted in early November. $(2 / 20 ; 5 / 20 ; 6 / 20)$ 